\title{
Oküloaurikülovertebral Spektrumlu Bir Olguda Göz Bulguları
}

\author{
Tuğba Göncü \\ Nevşehir Devlet Hastanesi Göz Sağlığı ve Hastalıkları Servisi, Nevşehir
}

\begin{abstract}
ÖZET
Oküloaurikülovertebral spektrumlu bir olguda göz bulguları

Hemifasiyel mikrosomi, birinci ve ikinci brankial ark anomalileri olan olgular Goldenhar sendromu olarak bilinmektedir, bu sendrom son yıllarda bu bulgulara mandibular, auriküler, oküler ve vertebral anomalilerin değişik kombinasyonlarını kapsayan klinik durumların eklenmesiyle oküloaurikülovertebral spektrum olarak adlandırılmaya başlanmıştır. Bu çalışmada hafif sistemik bulguların varlığında birden fazla oküler bulgunun birlikte görüldüğü yetişkin bir oküloaurikülovertebral spektrum olgusu ele alınmış ve oküler anomalileri olan olgularda ayırıcı tanıda oküloaurikülovertebral spektrumun düşünülmesini sağlamak amaçlanmıştır.
\end{abstract}

Anahtar kelimeler: Oküloaurikülovertebral spektrum, dermoid, kolobom

\section{ABSTRACT}

Ocular findings of a case with oculoauriculovertebral spectrum

The term oculoauriculovertebral spectrum is characterized by ocular, auricular and vertebral anomalies which was previously named as hemifacial microsomia, Goldenhar syndrome or first-second branchial arch anomaly. In this article, an adult case of oculoauriculovertebral spectrum with multiple ocular anomalies accompanying minimal systemic problem was presented and oculoauriculovertebral spectrum was mentioned as a differential diagnoses in cases with ocular anomalies.

Key words: Oculoauriculovertebral spectrum, dermoid, coloboma

\section{GiRiş}

$\mathrm{H}$ emifasiyel mikrosomi, birinci ve ikinci brankial ark anomalileri olan olgular Goldenhar sendromu olarak bilinmektedir. Son yıllarda bu bulgulara mandibular, auriküler, oküler ve vertebral anomalilerin değişik kombinasyonlarını kapsayan klinik durumların eklenmesiyle oküloaurikülovertebral spektrum (OAVS) olarak adlandırılmaktadır (1). Bu spektrum normal sayılabilecek kadar hafif bir tablodan ciddi formlara kadar uzanabilen çeşitli klinik bulgularla izlenebilmektedir ve zaman zaman yarık dudak-damak, makrostomi, renal, pulmoner ve kardiak malformasyonlar tabloya eşlik edebilmektedir (1-3).

Bu çalışmada göz tutulumunun daha belirgin olduğu yetişkin bir OAVS olgusu ele alınmış ve oküler anomalileri olan olgularda ayırıcı tanıda OAVS'nin düşünülmesini sağlamak amaçlanmıştır.

Yazıșma adresi / Address reprint requests to: Dr. Tuğba Göncü Nevşehir Devlet Hastanesi, Göz Sağlığı ve Hastalıkları Servisi, Nevşehir Telefon / Phone: +90-532-490-8102

Elektronik posta adresi / E-mail address: tubicon@hotmail.com Geliş tarihi / Date of receipt: 11 Şubat 2011 / February 11, 2011 Kabul tarihi / Date of acceptance: 18 Temmuz 2011 / July 18, 2011

\section{OLGU SUNUMU}

27 yaşında bayan hasta sağ göz kapağında şekil bozukluğu ve sağ gözde doğduğundan beri olan kitle şikayeti ile kliniğimize başvurdu. Hastanın öz geçmişinde ve soy geçmişinde spesifik bulgu yoktu. Akraba evliliği hikayesi yoktu. Hastanın yapılan oftalmik muayenesinde sol gözünün görme keskinliği 20/20 olup göz içi basıncı 14 mm Hg olarak ölçüldü. Bu gözün ön segment ve fundus muayeneleri doğal olarak değerlendirildi. Sağ gözünün ise en iyi düzeltilmiş görme keskinliği 20/30 olup göz içi basıncı 16 mm Hg olarak ölçüldü. Hastanın biyomikroskopik ön segment muayenesinde üst kapak orta 1/3'lük bölümünde kolobom, inferotemporalde limbusta $5 \times 4 \mathrm{~mm}$ büyüklüğünde dermoid tümör ve temporalde kantüsten başlayıp posteriorda orbita yağ dokusu ile kaynaşan lipodermoid kitle olduğu saptandı (Şekil 1). Hastanın diğer ön segment bulguları ve fundus muayenesi doğal idi. Kornea çapı sağ gözde $11.5 \mathrm{~mm}$ sol gözde ise $13 \mathrm{~mm}$ olarak ölçüldü. B mod ultrasonografide her iki gözde orbita yapıları doğal izlendi, gözün ön arka çap sağ gözde 23 mm ölçülürken sol gözde $23.5 \mathrm{~mm}$ olarak ölçüldü. Hastanın gözleri primer pozisyonda ortoforikti ve tüm bakış yönlerinde göz hareketleri 


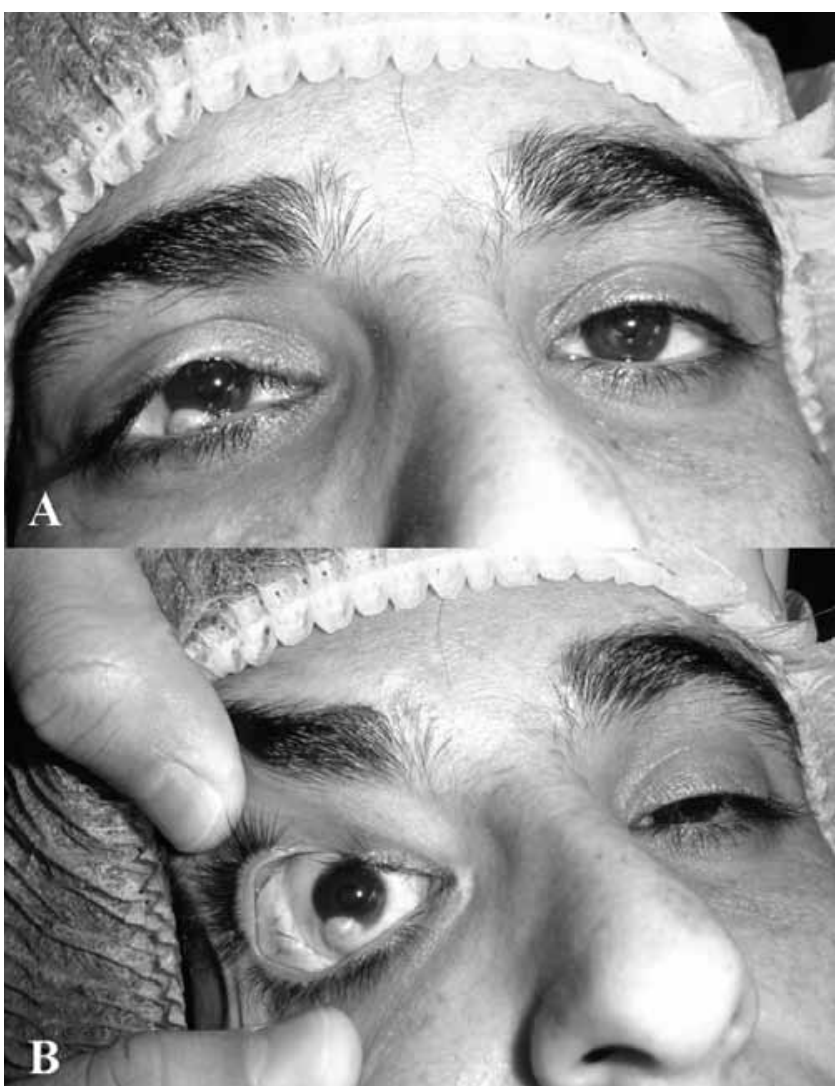

Şekil 1: A) Sağ gözde üst kapak kolobomu ve limbus inferotemporalinde limbal dermoid. B) Limbal dermoid ve temporal kantüsten başlayıp posteriorda orbita yağ dokusu ile kaynaşan üzerinde kıl folikülleri bulunan lipodermoid kitle.

doğaldı. Hastanın fizik muayenesinde sağ kulakta minimal şekil bozukluğu ve preauriküler cilt katlantısı izlendi. Dahiliye bölümü tarafından değerlendirilen hastada sistemik patoloji izlenmedi. Kulak burun boğaz muayenesinde ve işitme testlerinde patoloji izlenmedi.

\section{TARTIŞMA}

Oküloaurikülovertebral spektrum nadir görülen özellikle oküler, auriküler, mandibular malformasyonlarla karakterize gelişimsel bir bozukluktur. Etiyolojisi üzerinde literatürde farklı görüşler olmakla birlikte embriyonel gelişimin 4. ila 8. haftaları arasında birinci ve ikinci brankial arkların anormal gelişimi ve nöral krest hücre dağılım

\section{KAYNAKLAR}

1. Cohen MM Jr, Rollnick BR, Kaye Cl. Oculoauriculovertebral spectrum: an updated critique. Cleft Palate J 1989; 26: 276-286.

2. Kaye $\mathrm{Cl}$, Martin $\mathrm{AO}$, Rollnick $\mathrm{BR}$, et al. Oculoauriculovertebral anomaly: segregation analysis. Am J Med Genet 1992; 43: 913-917. bozukluğuna bağlı olduğu düşünülmektedir $(4,5)$. Literatürde tahmini insidansı $1 / 3500$ ile $1 / 5600$ arasında ve erkek/kadın oranı 3/2 olarak gösterilmektedir $(4,6)$. Olguların çoğunu sporadik vakalar oluştursa da literatürde otozomal dominant ve otozomal resesif geçiş gösteren aile serileri bildirilmiştir $(4,7,8)$. Karyotip incelemelerinde kromozomal bozukluk saptanmamıştır (9).

Mikrotia (küçük ve malforme kulak) varlığı veya preariküler cilt çıkıntıları varlığında hemifasyal mikrosomi asgari tanı kriteri olarak kabul edilmektedir $(4,7,10)$. Sporadik olgularda \%100 oranında kulak anomalileri (mikrotia, preariküler cilt çıkıntıları, dış kulak yolu problemleri), \%83 oranında fasiyel asimetri, \%43 oranında ağız anomalileri (makrostomi, yarık dudak, yarık damak), \%34 oranında göz anomalileri ve \%31 oranında vertebra anomalileri (skolyoz, hemivertebra, servikal füzyon) bildirilmiş̧ir $(8,10)$. Literatürde OAVS ile ilişkilendirilmiş göz bulguları limbal dermoid, lipodermoid, kapak kolobomu, pitozis, karinkül anomalileri, Duane retraksiyon sendromu, mikroftalmi, ve anoftalmi olarak belirtilmektedir (8,10-15). Göz bulguları içerisinde en sık dermoid görülür ve bir seride \%78 gibi yüksek bir oranda saptanmıştır ve olguların \%30-53'ü tek taraflı olduğu belirtilmiştir (12). Lipodermoid ise dermoide oranla daha seyrektir ve olguların \%47'sinde izlenmektedir (12). Yayınlanan bir çalışmada, OAVS sendromunda optik disk tilti, optik sinir hipoplazisi, retinal damarlarda kıvrımlanma artışı, maküla hipoplazisi gibi bulguların da izlendiği bildirilmiştir (16).

Olgumuzun kapak kolobomu, limbal dermoid ve orbital lipodermoid tümörü gibi göz bulguları, minimal auriküler deformitesi ve kulak önünde ise cilt katlantısı dışında başka sistemik bir bulgusu mevcut değildir. Kulak anomalleri varlığı, mevcut göz bulguları ile birlikte OAVS'u düşündürmektedir. Olgumuzda minimal sistemik bulguların varlığında birden fazla oküler bulguların birlikteliği dikkat çekmektedir.

Sonuç olarak OAVS normal sayılabilecek hafif olgulardan çok ciddi malformasyonlara kadar geniş bir spekturumu içerebilmektedir. Belirgin sistemik bulgular olmadan lipodermoid, dermoid ve kapak kolobomu gibi göz bulguları olan olgularda OAVS olabileceği akılda tutulmalıdır.

3. Ritchey ML, Norbeck J, Huang C, Keating MA, Bloom DA. Urologic manifestations of Goldenhar syndrome. Urology 1994; 43: 88-91.

4. Grabb WC. The first and second brachial arch syndrome. Plast Reconstr Surg 1965; 36: 485-508. 
5. Beauchamp GR, Knepper PA. Role of the neural crest in anterior segment development and disease. J Pediatr Ophthalmol Strabismus 1984; 21: 209-214.

6. Gorlin RJ, Pindborg JJ, Cohen MM Jr (Eds). Syndromes of the Head and Neck, 2nd Ed. New York: McGraw-Hill 1976: p. 546-552.

7. Rollnick BR, Kaye $\mathrm{Cl}$. Hemifacial microsomia and variants: pedigree data. Am J Med Genet 1983; 15: 233-253.

8. Tasse C, Majewski F, Böhringer S, et al. A family with autosomal dominant oculo-auriculo-vertebral spectrum. Clin Dysmorphol 2007; 16: 1-7.

9. Rao VA, Kaliaperumal S, Subramanyan T, Rao KR, Bhargavan R. Goldenhar's sequence with associated juvenile glaucoma in Turner's syndrome. Indian J Ophthalmol 2005; 53: 267-268.

10. Tasse C, Bohringer S, Fischer S, et al. Oculo-auriculo-vertebral spectrum (OAVS): clinical evaluation and severity scoring of 53 patients and proposal for a new classification. Eur J Med Genet 2005; 48: 397-411.
11. Strömland $K$, Miller $M$, Sjögreen L, et al. Oculo-auriculo-vertebral spectrum: associated anomalies, functional deficits and possible developmental risk factors. Am J Med Genet A 2007; 143A: 13171325.

12. Baum JL, Feingold M. Ocular aspects of Goldenhar syndrome. Am J Ophthalmol 1973; 75: 250-257.

13. Nijhawan N, Morad Y, Seigel-Bartelt J, Levin AV. Caruncle abnormalities in the oculo-auriculo-vertebral spectrum. Am J Med Genet 2002; 113: 320-325.

14. Yılmaz T, Çelebi S, Kibar Y, Özercan I, Kükner AŞ. Goldenhar sendromlu bir olgu. MN Oftalmoloji 2002; 9: 909-915.

15. Özkağnıcı A, Zengin N, Okudan S, Avunduk MC. Limbal dermoid nedeniyle opere edilen bir Goldenhar sendromu olgusu. T Oft Gaz 2000; 30: 513-516.

16. Margolis S, Aleksic S, Charles N, McCarthy J, Greco A, Budzilovich G. Retinal and optic nerve findings in Goldenhar-Gorlin syndrome. Ophthalmology 1984; 91:1327-1333. 